Nevertheless, it is necessary to ensure that these risks do not have serious consequences, for injury in an automobile accident may cause as much suffering as a wound sustained in war.

Thus, you have espoused the cause of first aid development, with the desire to serve, the will to do charitable work, which are the hall-marks of the Red Cross...

\title{
Republic of Vietnam
}

Our thanks go to $M r$. U. Schüle for the following article, written for the International Review, describing the training, in which he took an active part, of first-aiders in the Red Cross of the Republic of Vietnam. Mr. Schïle, until quite recently, was a member of the League of Red Cross Societies delegation in that country.

There are hundreds of young people in the Republic of Vietnam who ask nothing more than to help others. They are of the generation which is acquainted with war, danger and upheaval. They are an encouragement in these troubled times for the Red Cross in their country.

Training.-This is thorough, for these young people are often called upon to perform tasks which go beyond what is usually entrusted to a first-aider. It is divided into four main parts:

1. Courses covering all aspects of the Red Cross, its origin, history, international and national organization, the Geneva Conventions, the basic Red Cross principles, and the spirit which should be the motivation of all members of our movement. The National Society lays stress on this part of the training, for it has observed that young people outnumber adults in the Red Cross, of which the first-aiders are the very important " missionaries". That the Red Cross of the Republic of Vietnam enjoys considerable prestige is due to a great extent to its young first-aiders. They are everywhere 
where the Red Cross goes into action. Moreover, this part of their training ensures wide dissemination among youth of a knowledge of the Geneva Conventions.

2. The usual first-aid courses.

3. Supplementary courses on hygiene, communicable diseases and their prevention, and medicines. These young first-aiders also learn to administer injections properly. This is perhaps the trickiest part of their training. Normally first-aiders are not qualified to give injections, and first-aid courses do not ordinarily cover medicines. Anyone versed in first-aid as practised in countries at peace would be surprised to see the Vietnam first-aiders giving injections or intravenous perfusions. But the shortage of medical and paramedical personnel in Vietnam is severe and, consequently, first-aiders do not have "professionals" on hand as in Europe. It was therefore decided to introduce these courses in the training of first-aiders to enable them to act efficiently in case of need. At the same time, stress is laid on the fact that only a doctor is entitled to prescribe medicaments and that the first-aider may only administer them when they have been so prescribed. The dangers of mis-use of medicines is not overlooked, and experience has shown that firstaiders do not exceed the bounds of their knowledge and that the training they receive in this field is justified by present circumstances.

4. The final stage of training includes a fortnight's service at a hospital, to give the first-aiders opportunities to apply their knowledge in the treatment of sick and wounded patients, and at the same time contribute to the staffing of the hospital. They are a great help to hospitals when there is a large number of newly arrived casualties.

The final examinations are always very stiff, and none but the really proficient candidates are awarded a diploma.

Their Job.-What work do the young first-aiders do at this moment?

First and foremost of the young first-aiders' activities is their participation in Red Cross relief work. They organize efficiently the distribution of food to needy families uprooted by war or natural 
disaster. ${ }^{1}$ It is thanks to them that the National Society can give effect to one of the major principles of its actions, namely, that Red Cross relief should reach the beneficiaries direct through the Society's own agents. Distribution has often to be made in villages where only the Red Cross has access, but the first-aiders go to them with complete confidence in the protection of the red cross.

Relief actions are not their only activity. They are also active in the medico-social field. When fire occurs in a straw hut district, Red Cross first-aiders are the first on the scene to set up a first-aid post and to man it round the clock for several days. They often go to the outskirts of the town or to refugee camps with a doctor (with an ICRC doctor-delegate last summer) to organize medical consultations. The doctor examines the patients and prescribes for them, and the first-aider acts as nurse and supervises the treatment recommended by the doctor.

During the fighting in 1968, first-aiders often performed acts of courage. They collected the wounded in the fighting areas in Saigon. At Vinh Long it was impossible to reach the hospitals during the first few days of the Têt offensive, and it was the first-aiders who, on their own initiative, set up first-aid posts on the outskirts of the town to take care of casualties. Pharmacists spontaneously offered medical supplies; a proof of their confidence in the Red Cross. As a result, and thanks to their extensive training, the first-aiders saved a number of lives.

In other provinces they provided permanent relief staff for hospitals, in order to help hospital personnel and even to stand in for those who were for several days unable to reach the hospital. After these attacks, many families who had to flee their homes were sheltered in reception centres. In several towns these people were helped by Red Cross first-aiders who looked after children, cooked meals and saw to it that rules of hygiene were observed. In some provinces they are responsible for hygiene campaigns, for measures to reduce the rat population and for vaccination. Elsewhere they disseminate knowledge of the Geneva Conventions and Red Cross principles in schools.

1 Plate: Young Red Cross-first-aiders distributing dried fish to the homeless. They also register refugees. 
All these young volunteers carry out their duties with enthusiasm and dedication. For the Vietnam Red Cross these first-aiders are an assurance of being able to discharge its humanitarian mission now and in the future.

\section{Haiti}

The official inauguration ceremony of the new headquarters of the Haiti Red Cross took place at Port-au-Prince on December 12, 1968, which also symbolized the remarkable efforts made by the Red Cross over a long period inspired by Dr. Victor Laroche, its new President.

Dr. Duvalier, President of the Republic, attended the event and leading personalities of Haiti, members of the Society's executive committee together with Mr. Pierre Gaillard and Mr. José Gomez Ruiz, representing the ICRC and League respectively, were present.

The new headquarters, consisting of two modern buildings, one for offices and the other for a large auditorium, had been donated to the Haiti Red Cross by the President of the Republic, who was warmly thanked by Dr. Laroche. He then ended his speech by pointing out that the new headquarters are intended to become a centre for medico-welfare, educational, training and assistance work.

"This building which is a concrete example of the highest human aspirations will in future be the planning centre for Haiti Red Cross activities. At this new stage a definition must be made of the concept which should guide its action and indicate its technical and social role according to the direction desired and expressed by our honorary President.

"If the National Red Cross Societies are ruled by the same fundamental principles and have to resolve many similar problems, each of their action programmes depends on the particularities of their own respective countries. Co-operating in the solution of problems raised by the suffering and needs of the Haitian popula- 